\title{
COMPORTAMENTO DE PARAFUSOS CORTICAIS SUBMETIDOS A ENSAIO DE TORÇÃO MANUAL E DE TORÇÃO EM MÁQÜINA
}

\author{
BEHAVIOR OF CORTICAL SCREWS SUBMITTED TO MANUAL TORSION ASSAY AND \\ AUTOMATED TORSION ASSAY
}

Suraya Gomes Novais Shimano ${ }^{1}$, Antônio Carlos Shimano²

\begin{abstract}
RESUMO
Parafusos corticais são submetidos a tensões de torção durante sua inserção e retirada. Portanto, um dos objetivos deste trabalho foi avaliar o comportamento mecânico dos parafusos corticais de aço inoxidável, quando submetidos a dois tipos de ensaios de torção, o manual e o realizado em uma máquina de torção. O outro objetivo foi analisar o local da fratura resultante dos dois ensaios, por meio de Microscopia Eletrônica de Varredura. Foram utilizados dez parafusos corticais de aço inoxidável. Cinco parafusos foram submetidos ao ensaio de torção manual e os outros cinco parafusos foram ensaiados em máquina de torção. Foram calculadas suas propriedades e a análise do local da fratura foi feita por Microscopia Eletrônica de Varredura. O ensaio de torção manual mostrou-se impreciso para o cálculo das propriedades mecânicas e, por isso, contra-indicado para a determinação do comportamento mecânico de parafusos corticais de aço inoxidável. A torção na máquina apresentou uma metodologia mais rígida e, portanto com resultados mais confiáveis. As fraturas dos parafusos, tanto do ensaio de torção manual quanto do ensaio de torção na máquina, apresentaram padrões sem distinções.
\end{abstract}

Descritores: Torção, Parafusos ósseos; Teste de materiais; Placas ósseas; Aço inoxidável.

Citação: Shimano SGN, Shimano AC. Comportamento de parafusos corticais submetidos a ensaio de torção manual e de torção em máquina. Acta Ortop Bras. [periódico na Internet]. 2008; 16(2):81-84. Disponível em URL: http://www.scielo. br/aob.

\section{INTRODUÇÃO}

Atualmente a análise da qualidade mecânica de um implante em forma de parafusos corticais, é feita através de teste de torção manual, utilizando um torquímetro. Nestes testes consideram-se apenas os valores de torque de ruptura e ângulo de ruptura destes parafusos. Não é considerado relevante todo o comportamento mecânico destes implantes.

O entendimento do comportamento mecânico permite que se avalie a resistência desses parafusos durante todo o período em que este exerce sua função de fixação: na inserção, no período de implantação e na retirada.

O ensaio mecânico de torção não é utilizado para especificações de materiais. É indicado para peças que, na prática, são submetidas aos esforços de torção como: molas, barras de torção, parafusos, dentre outros ${ }^{(1)}$.

Isto ocorre com um parafuso ósseo cortical que, quando é utilizado na fixação de placas para estabilização de fraturas em ossos

\section{SUMMARY}

Cortical screws are submitted to torsional forces during its insertion and removal. Therefore, one of the purposes of this research was to evaluate the mechanical behavior of stainless steel cortical screws submitted to manual torsion test and automated torsion test. The secondary objective was to analyze the fracture area with a scanning electron microscope. Ten cortical stainless steel screws have been used. Five screws were submitted to the manual torsion test and five screws were tested on a torsion machine. Their properties were calculated and the fracture area was analyzed. The manual torsion test has shown to be inaccurate for the calculation of mechanical properties. Therefore, it is contraindicated for identifying the mechanical behavior of cortical stainless steel screws. The automated torsion test showed a more rigid methodology and therefore more reliable results. Screws fractures, both on manual and automated torsion assays, presented no different patterns.

Keywords: Torsion, Bone screws, Materials testing; Bone plates; Stainless Steel.

Citation: Shimano SGN, Shimano AC. SEM TITULO EM INGLES. Acta Ortop Bras. [serial on the Internet]. 2008; 16(2):81-84. Available from URL: http://www.scielo. br/aob.

longos, é submetido a um momento torcional ou torque (2). Este torque é, aparentemente, responsável pela ancoragem do parafuso ao osso, mas se for aplicado em excesso pode provocar a fratura do parafuso, caso este não possua um coeficiente de segurança para suportar o carregamento mecânico sem romper, ou se não estiver de acordo com as normas de fabricação(3).

Com relação aos tipos de fraturas resultantes de um carregamento em torção, em um corpo cilíndrico, sujeito à torção, há tensões máximas de cisalhamento situadas em dois planos perpendiculares entre si, sendo um deles perpendicular e outro paralelo ao seu eixo longitudinal ${ }^{(1)}$. Assim, a ruptura de um metal dúctil ocorre por deslizamento ao longo dos planos onde se situam tensões máximas de cisalhamento, portanto o aspecto da fratura é plano. Já um metal frágil rompe ao longo de um plano perpendicular à direção da tensão de tração, isto é, uma tensão que faz um ângulo de $45^{\circ}$ com o eixo longitudinal do corpo de prova, resultando em uma ruptura em hélice.

Trabalho realizado no Departamento de Biomecânica, Medicina e Reabilitação do Aparelho Locomotor (Laboratório de Bioengenharia) da Faculdade de Medicina de Ribeirão Preto da Universidade de Sáo Paulo.

Endereço para correspondência: Av. Bandeirantes, 3.800, Laboratório de Bioengenharia - Campus Universitário, Monte Alegre, Ribeirão Preto, SP. - Brasil -CEP: 14.049-900 - E-mail: surayagnovais@yahoo.com.br; ashimano@fmrp.usp.br

1. Doutoranda em Ciências Médicas pelo Departamento de Biomecânica, Medicina e Reabilitação do Aparelho Locomotor da Faculdade de Medicina de Ribeirão Preto - USP. Mestre em Bioengenharia pela Faculdade de Medicina de Ribeirão Preto - USP.

2. Professor Doutor do Departamento de Biomecânica, Medicina e Reabilitação do Aparelho Locomotor da Faculdade de Medicina e Ribeirão Preto - USP. 
Portanto, um dos objetivos deste trabalho foi realizar em parafusos corticais de aço inoxidável, dois tipos de ensaios de torção, o manual e o realizado em uma máquina de torção. O outro objetivo foi analisar o local da fratura resultante dos dois ensaios, por meio de microscopia eletrônica de varredura.

\section{MATERIAL E MÉTODO}

Foram utilizados dez parafusos corticais de aço inoxidável $\mathrm{Cr} \mathrm{Ni}$ Mo - ASTM F-138, fornecidos pela Baumer ${ }^{\circledR}$ (fabricante nacional de produtos e dispositivos ortopédicos). Todos os parafusos foram de um mesmo tipo (cortical), de uma mesma medida $(4,5 \mathrm{~mm}$ de diâmetro) e obtidos aleatoriamente de três lotes distintos. Destes parafusos cinco foram submetidos ao ensaio de torção manual e os outros cinco parafusos foram ensaiados em máquina de torção.

\section{Ensaio de Torção Manual}

Para o ensaio de torção manual foi utilizado um torquímetro digital Mackena ${ }^{\circledast}$, modelo MK-20XX, com capacidade de 10 N.m e precisão de $0,01 \mathrm{~N} \cdot \mathrm{m}$, para a quantificação do torque imposto ao parafuso, a cada angulação. Este modelo de torquímetro é o mesmo utilizado pelos fabricantes de implantes ortopédicos para testar a qualidade mecânica dos parafusos.

Para a realização deste ensaio, os parafusos foram travados em uma morsa, mantendo seu recesso hexagonal voltado para cima e deixados 5 fios de rosca livres, como exige a NBR ISO 6475:1997(5). Foi confeccionada uma peça de encaixe hexagonal nas dimensões do recesso hexagonal da cabeça do parafuso, seguindo os padrões especificados na NBR ISO 8319-1: 1998(4), que foi acoplada ao torquímetro.

Com a peça de encaixe hexagonal do torquímetro acoplada ao sextavado da cabeça do parafuso, mantendo um ângulo de $90^{\circ}$ entre o braço do torquímetro e o eixo longitudinal do parafuso, um examinador iniciou um movimento circular, em sentido horário, com velocidade dentro dos valores exigidos na norma (1 a 5 rotações/ minuto), até a ruptura total do parafuso (Figura 1).

A mensuração do torque foi feita simultaneamente por dois examinadores, o primeiro fez a leitura dos ângulos e o segundo anotou o torque correspondente ao ângulo a cada $10^{\circ}$ de deformação angular do parafuso. $O$ ângulo de torção foi medido através de um goniômetro, que teve seu braço móvel acoplado ao torquímetro e seu braço fixo travado à morsa (Figura 2).

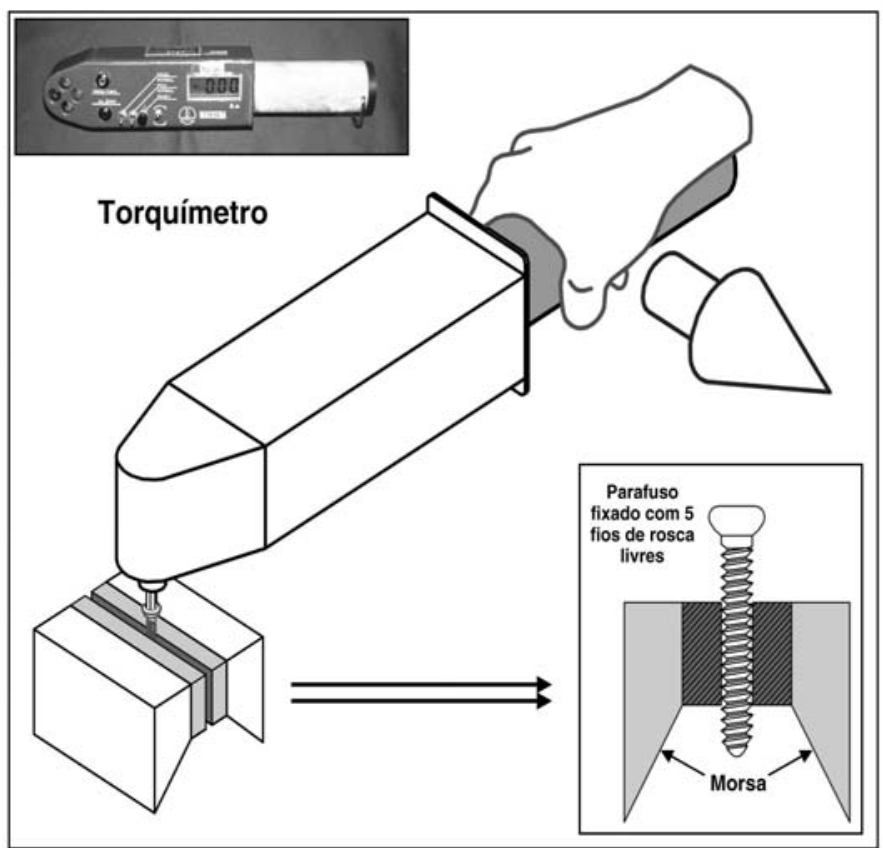

Figura 1 - Detalhes para utilização do torquímetro na realização do ensaio de torção manual.
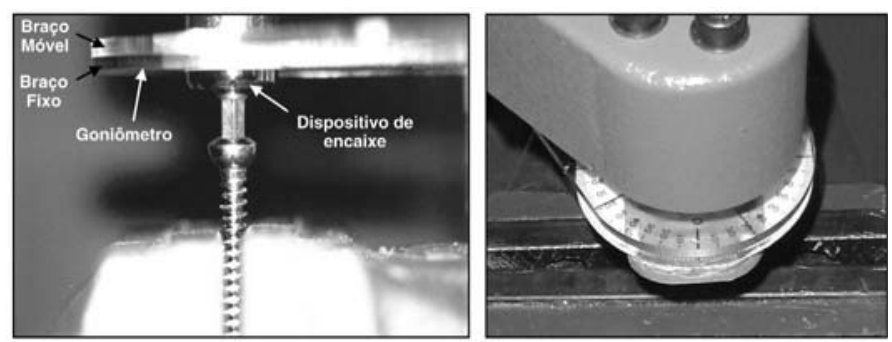

Figura 2 - Posicionamento do goniômetro para leitura dos ângulos. O braço móvel foi acoplado no goniômetro e o braço fixo travado na morsa.

\section{Ensaio de torção em Máquina de Torção}

Para a realização deste ensaio foi utilizada uma Máquina de Torção Gunt Hamburg. ${ }^{\circledR}$ - WP 510 - 200N.m, acoplada a um microcomputador do Laboratório de Ensaios Mecânicos do Centro Estadual de Educação Tecnológica Paula Souza (Escola Técnica Estadual José Martimiano da Silva).

Foram confeccionados na Oficina de Precisão da Prefeitura do Campus da USP de Ribeirão Preto, dois acessórios para acoplar nas extremidades fixa e giratória da máquina de torção. $O$ primeiro acessório foi acoplado à extremidade giratória da máquina e possuía uma ponta hexagonal feita de acordo com a NBR ISO 8319$1: 1998^{(4)}$, para encaixar na cabeça do parafuso. Na extremidade oposta (fixa) foi acoplado o outro acessório que possuía um encaixe para travar o parafuso, como uma morsa (Figura 3).

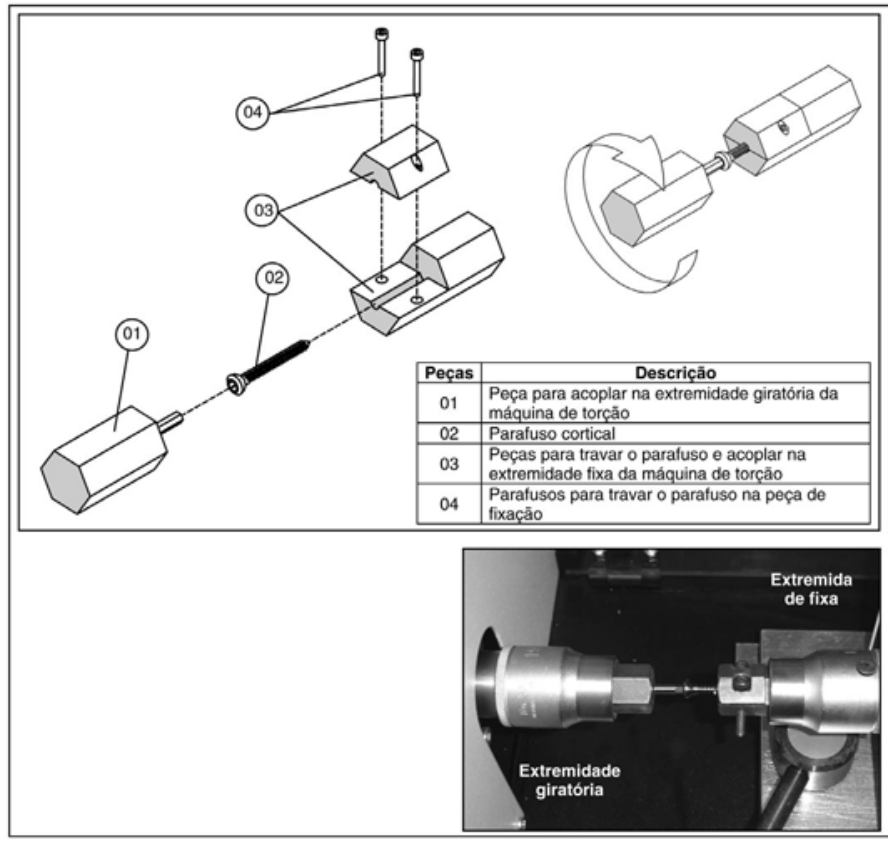

Figura 3 - Detalhes da fixação do parafuso no acessório, acoplamento dos acessórios às extremidades fixa e giratória da máquina de torção e, encaixe do parafuso com a ponta hexagonal do acessório.

Os dois sentidos de rotação (horário e anti-horário) e as velocidades de ensaio foram pré-estabelecidos no software WP 510 Torsional Tester instalado no microcomputador. Somente quatro velocidades estavam disponíveis para o ensaio: 50\% $\mathrm{min}, 100 \%$ min, $200 \%$ min e $500 \%$ min.

Durante o ensaio, o parafuso permaneceu com apenas cinco fios de rosca livres e o restante fixos na peça de fixação, como exige a NBR ISO 6475:1997(5). O sentido da rotação foi horário e a velocidade rotacional utilizada foi de $500 \% / \mathrm{min}$, também de acordo da exigência da norma NBR ISO 6475:1997(5).

O software, forneceu o gráfico torque $x$ deformação angular. Através destes gráficos puderam ser calculadas as seguintes propriedades 
mecânicas: torque máximo; torque no limite de proporcionalidade, rigidez torcional, e tenacidade torcional.

\section{Microscopia eletrônica de varredura}

Para análise mais detalhada das fraturas dos parafusos após os ensaios de torção foi feita a microscopia eletrônica de varredura. Esta análise foi realizada no Laboratório de Microscopia Eletrônica do Departamento de Biologia Celular e Molecular e Bioagentes Patogênicos da Faculdade de Medicina de Ribeirão Preto - USP. O microscópio utilizado foi da marca Scanning Microscope ${ }^{\circledR}$, modelo JSM - 5200, com capacidade de aumento máximo de até 200.000 vezes. O aumento utilizado para análise da imagem dos parafusos foi de 35 vezes.

A metodologia do posicionamento dos parafusos e captura de imagens foi a padrão, realizada em análises de metais. As fotografias foram feitas com um filme fotográfico preto e branco, $120 \mathrm{~mm}$ (Kodak ${ }^{\circledR}$, modelo $\left.T_{\text {máx }} 100\right)$.

\section{Análise Estatística}

Para a análise estatística foi utilizado o programa SigmaStat ${ }^{\circledR}$ v.2.03. Inicialmente foram realizadas análises de normalidade e de igualdade de variância. Para a comparação entre o grupo de torção manual e o grupo de torção em máquina, foi utilizado o teste $t$ de Student., com valor de 5\% como nível de significância.

\section{RESULTADOS}

Foram traçados gráficos torque versus deformação angular, onde os valores do torque (N.m) foram registrados na ordenada e na abscissa foram registrados os valores do deslocamento angular (graus). Destes gráficos foram calculadas algumas propriedades mecânicas (Tabela 1).

A análise estatística das propriedades mecânicas revelou que entre os parafusos submetidos à torção manual e os submetidos à torção em máquina de torção, houve diferença para mais nos parafusos submetidos à torção manual no torque no limite de proporcionalidade e para mais nos parafusos submetidos à torção em máquina na tenacidade torcional. Porém, não houve diferença no torque no limite máximo e na rigidez torcional.

Comparando as imagens obtidas pela microscopia eletrônica de varredura, não houve diferença entre a fratura dos parafusos submetidos à torção manual e a fratura dos parafusos submetidos à torção na máquina de torção, mas pode-se ver a ruptura em hélice dos parafusos - característica de um material dúctil- com estriações e deformação da rosca adjacente à área de fratura.

Tabela 1 - Médias das propriedades mecânicas obtidas dos ensaios de torção em parafusos corticais de aço inoxidável

\begin{tabular}{c|c|c|c}
\hline $\begin{array}{c}\text { Propriedades } \\
\text { Mecânicas }\end{array}$ & $\begin{array}{c}\text { Torção } \\
\text { Manual }\end{array}$ & $\begin{array}{c}\text { Torção em } \\
\text { Máquina }\end{array}$ & $\mathrm{p}$ \\
\hline $\begin{array}{c}\text { Torque no Limite de } \\
\text { Proporcionalidade } \\
\text { (N.m) }\end{array}$ & $\begin{array}{c}4,26 \pm \\
0,63\end{array}$ & $2,96 \pm 0,29$ & 0,012 \\
\hline $\begin{array}{c}\text { Torque Máximo } \\
\text { (N.m) }\end{array}$ & $\begin{array}{c}5,60 \pm \\
0,80\end{array}$ & $5,72 \pm 0,16$ & 0,625 \\
\hline $\begin{array}{c}\text { Rigidez Torcional } \\
\text { (N.m/grau) }\end{array}$ & $0,379 \pm$ & $0,350 \pm$ & 0,673 \\
\hline $\begin{array}{c}\text { Tenacidade Torcional } \\
\text { (N.m/grau) }\end{array}$ & $1691 \pm$ & $2431 \pm 215$ & 0,002 \\
\hline
\end{tabular}

\section{DISCUSSÃO}

O método de torção manual foi escolhido por ser utilizado nas empresas para testar os parafusos por elas fabricados, porém apresentou dificuldades importantes como:

1. Para a realização da leitura da deformação angular e do valor de torque correspondente, devido à velocidade do ensaio e à incapacidade do torquímetro em armazenar dados, foi necessária a presença de três pessoas: a primeira fazendo a aplicação do torque, a segunda fazendo a leitura angular e a terceira anotando o torque referente ao ângulo correspondente.

2. A manutenção da perpendicularidade entre o braço do torquímetro e o eixo axial do parafuso, submetendo-o a outros esforços como o de flexão, não sendo, portanto, um ensaio puro de torção. Grande parte do torque pode ter sido perdida com a mudança da angulação entre o braço do torquímetro e o eixo axial do parafuso.

3. A variação da velocidade de ensaio, pois após o limite de proporcionalidade, a resistência oferecida pelo material diminui, aumentando, conseqüentemente a velocidade do ensaio, que é manual e, portanto inconstante. Mesmo estando de acordo com a NBR ISO 6475:1997(5), que determina uma variação de velocidade de 1rpm a 5 rpm, esta variação de velocidade pode alterar os resultados das propriedades mecânicas. Portanto, a determinação de uma velocidade constante de ensaio deveria ser especificada em norma para que os resultados obtidos desses ensaios fossem mais fidedignos.

4. O design do torquímetro, que obrigou o examinador a mudar de mão a, aproximadamente, $200^{\circ}$ de deformação angular, desacelerando o ensaio.

5. Na interpretação dos dados obtidos nos ensaios e cálculo das propriedades mecânicas, observou-se que o número de pontos usados na confecção dos gráficos foi muito pequeno, causando provável imprecisão nos resultados. Exemplificando, na maioria dos gráficos, há somente um par de coordenadas $(X, Y)$ até o ponto considerado como limite de proporcionalidade, o que pode ocultar do examinador dados importantes. Apesar disto, este traçado gráfico foi utilizado por autores como Browner et al. .(6) $^{(6}$.

Esta imprecisão na obtenção dos dados pode ter mascarado o real valor do torque no limite de proporcionalidade, que apresentou valores estatisticamente diferentes com relação aos grupos submetidos à torção em máquina. Porém, esta metodologia de obtenção dos valores de torque e de deformação angular é a recomendada pela NBR ISO 6475:1997(5) e é utilizada por diversos autores como Browner et al.(6), Müller et al..$^{(7)}$ e Abel e Sun ${ }^{(8)}$ para análise das propriedades mecânicas de implantes.

Autores como Collinge et al. ${ }^{(9)}$ limitam-se a avaliar somente o torque de ruptura e o local da ruptura. Outros como Abel e Sun ${ }^{(8)}$, apesar de usarem uma máquina de torção, tiveram de fazer uma anotação manual das medidas, o que também dificulta o método e pode mascarar os resultados.

Uma dúvida freqüente durante a aplicação desta metodologia recomendada, mas não justificada pela NBR ISO 6475:1997(5) foi o porquê de manter cinco fios de rosca expostos para a imposição do torque, se, na prática, o parafuso permanece totalmente inserido. Com esta metodologia, a fratura ocorre, aproximadamente, na terceira rosca. Esta poderia ocorrer na área de encaixe com a placa ou logo abaixo da cabeça do parafuso se este estivesse totalmente fixo na morsa, com exposição apenas da cabeça.

Trabalhos como os de Abel e Sun ${ }^{(8)}$ observaram leve deformação da cabeça dos parafusos de localização mais central da placa, após ensaio de torção do conjunto placa-parafuso. A aplicação de uma metodologia que difere da atual norma poderá obter resultados mais próximos a este ao submeter à torção apenas o parafuso cortical.

Por outro lado, a máquina de torção foi de fácil manuseio e interpretação dos dados. Porém, a restrição quanto ao controle da velocidade de ensaio a apenas quatro valores, poderia dificultar o uso da máquina para o uso em ensaios de diferentes implantes, visto que estes devem obedecer a valores de velocidades préestabelecidos em normas. 
Como discutido por Abel e Sun ${ }^{(8)}$, não há metodologia normatizada satisfatória para testes de torção em placas óssea. O mesmo problema apresenta-se com os parafusos ósseos.

Houve uma limitação com relação à determinação do módulo de elasticidade ou do momento torcional em parafusos, pois não foi possível determinar a secção circular desses. A determinação do valor de tensões dependente diretamente da secção circular. Por isso determinamos somente as propriedades mecânicas: torque no limite de proporcionalidade, o torque máximo, rigidez torcional e tenacidade torcional dos parafusos.

Com relação às propriedades mecânicas obtidas através dos cálculos baseados nos traçados dos gráficos torque $\mathrm{x}$ deformação angular observou-se que:

No torque no limite de proporcionalidade, a diferença estatística observada entre os parafusos submetidos à torção manual e os submetidos à torção em máquina evidencia não uma superioridade na qualidade dos parafusos, mas um problema metodológico já abordado nesta discussão (sobre o número de pontos usados na confecção dos gráficos ser muito pequeno, causando provável imprecisão nos resultados). Em um gráfico com um número maior de pontos pode-se observar com exatidão o último ponto onde os valores de torque e deformação angular aumentam proporcionalmente.

No torque máximo, a semelhança estatística demonstra não haver dificuldades no cálculo desta propriedade mecânica, que rotineiramente, é o único valor avaliado por fabricantes de parafusos corticais para avaliar a qualidade mecânica deste implante.

Na rigidez torcional, foi observada leve superioridade dos valores dos parafusos que foram submetidos à torção manual, que não fol confirmada pelo teste estatístico, provavelmente devido aos altos desvios-padrão. Suspeita-se que uma amostra maior, evidenciaria alguma diferença estatística entre os parafusos que sofreram torção manual e os que foram submetidos à torção em máquina e, com isso, o problema metodológico do ensaio de torção manual reapareceria e mostraria que o cálculo das propriedades mecânicas relacionadas à zona elástica do material, como a rigidez, possivelmente não apresentam precisão de resultados como os submetidos à torção na máquina de torção.

$\mathrm{Na}$ tenacidade torcional, a diferença significativa para menos dos parafusos que foram ensaiados manualmente com relação aos ensaiados em máquina de torção pode ter ocorrido devido à metodologia de ensaio de torção manual, onde há controle subjetivo da velocidade imposta pelo examinador. Esta velocidade variada pode ter sobrecarregado mais os parafusos desse grupo e por isso a tenacidade torcional apresentou-se menor.

Através das imagens por MEV, observou-se que não há diferenças qualitativas entre os resultados das duas metodologias utilizadas. Para tanto, são necessários outros métodos de quantificação.
Para a realização de um ensaio mecânico, não há diferenças significativas entre as metodologias propostas pelas várias associações mundiais de normas técnicas ${ }^{(1)}$. Porém, normas que contêm uma metodologia muito generalizada, possibilitam a realização de uma variedade de metodologias que se encaixam nas especificações contidas na norma. Esta variedade resulta em dados diferentes que não podem ser comparados aos dados obtidos em outros ensaios, e que podem culminar em uma classificação equivocada de um implante, atribuindo a este característica que não são peculiares do mesmo.

Segundo Laing ${ }^{(10)}$, a organização de normas internacionais e os procedimentos para sua escrita são realizados com o trabalho cooperativo entre cirurgiões, fabricantes e pesquisadores.

Estas normas pré-determinam valores e metodologias a serem seguidas e cumpridas por fabricantes (para garantir a qualidade físico-química do implante), por pesquisadores (para que os resultados experimentais possam ser comparados e discutidos) e por cirurgiões (para garantir um maior percentual de resultados positivos nos pós-operatórios). Com isto, o maior beneficiado será por direito, o público, o cidadão enfermo.

Como as Normas Brasileiras somente pré-determinam o torque de ruptura e o ângulo de ruptura, as análises desta pesquisa oferecem valores de outras propriedades mecânicas obtidas através de uma metodologia com poucas variáveis, pois pré determinou-se o posicionamento em um mesmo eixo da chave e do parafuso e a velocidade constante. Assim houve a possibilidade de uma análise mais fidedigna do comportamento mecânico.

Assim, como já abordado por Laing ${ }^{(10)}$, para atingir uma finalidade desejada como a análise do comportamento mecânico, deve-se primeiramente determinar os pontos críticos e posteriormente montar um novo método. Desta maneira, permite-se que estudos posteriores possam seguir uma especificação mais rígida e detaIhada, proporcionando resultados mais confiáveis e comparações entre diferentes estudos.

\section{CONCLUSÃO}

O ensaio de torção manual mostrou-se impreciso para o cálculo das propriedades mecânicas de materiais de implantes na forma de parafusos corticais e, por isso, contra-indicado para a determinação do comportamento mecânico. A torção na máquina apresentou uma metodologia mais rígida e portanto resultados mais confiáveis. E, as fraturas dos parafusos, tanto do ensaio de torção manual quanto de torção em máquina, apresentaram padrões sem distinções.

\section{AGRADECIMENTOS}

À CAPES, Coordenação de Aperfeiçoamento de Pessoal de Nível Superior, pela concessão de bolsa de Mestrado. E a Baumer ${ }^{\circledR}$ S.A., pela doação dos parafusos.

\section{REFERÊNCIAS}

1. Souza SA. Ensaios mecânicos de materiais metálicos. 5a. ed. São Paulo: Edgard Blücher Ltda; 1982

2. Hughes AN, Jordan BA. The mechanical properties of surgical screws and some aspects of insertion practice. Injury. 1972; 4:25-38.

3. Oni OA, Batchelor JS. Investigation of the torque-tension characteristics of a flanged external fixator pin. Biomaterials. 1995;16:1279-80.

4. Associação Brasileira de Normas Técnicas - NBR ISO 8319-1. Instrumentos Ortopédicos - conexões de ferramenta. Parte 1: chaves para uso com parafusos com encaixe hexagonal na cabeça; 1998

5. Associação Brasileira de Normas Técnicas - NBR ISO 6475. Implantes para cirurgia - parafusos ósseos metálicos com rosca assimétrica e superfície inferior da cabeça de forma esférica - requisitos mecânicos e métodos de ensaio; 1987.
6. Mazzoca AD, Caputo AE, Browner BD, Mast JW, Mendes MW. Principles of internal fixation. In: Browner BD, Jupiter JB, Levine AM, Trafton PG. Skeletal trauma: basic science, management and reconstruction. 3th. Philadelphia: Saunders; 2003 p. 195-249.

7. Perren SM, Mathys R, Pohler O. Implantes e materiais na fixação de fraturas. In: Rüedi, TP, Murphy, WM. Princípios AO do tratamento das fraturas. Tradução de Jacques Vissoky. Porto Alegre: Artmed; 2002

8. Abel EW, Sun J. Mechanical evaluation of a new minimum-contact palate for internal fracture fixation. J Orthop Trauma. 1998; 12:382-6.

9. Collinge CA, Stern S, Cordes S, Lautenschlager EP. Mechanical properties of small fragment screws. Clin Orthop Relat Res. 2000; (373):277-84.

10. Laing P. World standards for surgical implants: an american perspective. Biomaterials. 1994;15:403-7 